\title{
АКТУАЛЬНЫЙ ВОПРОС
}

П.А. Цыганков

DOI: 10.7256/2305-560X.2013.3.8977

\section{НЕГОСУДАРСТВЕННЫЕ УЧАСТНИКИ \\ МИРОВОЙ ПОЛИТИКИ: ВЗАИМОДЕЙСТВИЕ \\ С ГОСУДАРСТВАМИ И МЕЖПРАВИТЕЛЬСТВЕННЫМИ ОРГАНИЗАЦИЯМИ}

\begin{abstract}
Аннотация. В статье рассматриваются проблемы многообразия негосударственных акторов (НГА) и их взаимодействия с государственными и надгосударственными международными субъектами. Возросшая роль НГА в международных отношениях и их влияние на мирополитические процессы - очевидная данность, признаваемая практически всеми наблюдателями и исследователями. Международные неправительственные организации (МНПо) участвуют в решениях, принимаемых институтами ООН, а также структурами Евросоюза и иных международных организаций. Они воздействуют на общественное мнение, привлекая внимание к нарушению прав человека; без них не обходятся гуманитарные операции и ликвидация последствий гуманитарных катастроф; они оказывают благотворительную помощь нуждающимся. Неправительственные организации содействуют развитию экономически бедных регионов и стран; выступают в защиту окружающей среды; объединяют группы ученых и других профессионалов в крупные международные ассоциации, способствующие прогрессу науки, техники, экономики и социально-политическим преобразованиям обществ. Наконеи, МНПО вносят серьезный вклад в развитие международного права; формируют в международных отношениях и мировой политике новый моральный климат; стимулируют активность гражданского общества и солидарность в причастности к глобальным проектам по справедливому переустройству мира.
\end{abstract}

Ключевые слова: международные отношения, мировая политика, негосударственные акторы, дипломатия, государство, политическая система, политический процесс, международные институты, процедуры, ценности.

$\mathrm{B}$ озросшая роль НГА в международных отношениях и их влияние на мирополитические процессы - очевидная данность, признаваемая практически всеми наблюдателями и исследователями. МНПО участвуют в решениях, принимаемых ЭКОСОС и др. институтами ООН, а также структурами Евросоюза и иных международных организаций. Они воздействуют на общественное мнение, привлекая внимание к нарушению прав человека; без них не обходятся гуманитарные операции и ликвидация последствий гуманитарных катастроф; они оказывают благотворительную помощь нуждающимся. Неправительственные организации содействуют развитию экономически бедных регионов и стран; выступают в защиту окружающей среды; объединяют группы ученых и других профессионалов в крупные международные ассоциации, способствующие прогрессу науки, техники, экономики и социально-политическим преобразованиям обществ. Наконец, МНПО вносят серьез- ный вклад в развитие международного права; формируют в международных отношениях и мировой политике новый моральный климат; стимулируют активность гражданского общества и солидарность в причастности к глобальным проектам по справедливому переустройству мира.

Большинство исследователей сходятся и в том, что транснациональные корпорации и другие бизнес-структуры заметно меняют облик и само существо мировой экономики. По данным $\mathrm{OOH}$ уже в 2003 г. свыше 50000 ТНК обеспечивали более трети всего мирового экспорта. Транснациональный капитал становится все более глобальным, играя растующую роль в экономическом регулировании. Многие авторы подчеркивают увеличение его независимости от государств в способах управления, инвестициях, в найме персонала и т.п. ${ }^{1}$

Samy Cohen. La Résistance des États. La démocratie face aux défis de la mondialisationé Éd. du Seuil, 2003, p. 218. 
Нарастающая динамика и объем транснациональных потоков - финансовых, торговых, информационных, многообразных видов туризма, миграции настолько высоки, что они не могут не выбиваться из-под контроля правительств и не оказывать влияния на межгосударственные взаимодействия и глобальную политику. Так, например, благодаря сверхбыстрым средствам коммуникации, финансовые фонды способны сегодня моментально перемещаться из одной страны в другую без контроля, а нередко даже и без ведома со стороны государства. С другой стороны, возросшие за последние десятилетия туристические потоки не только вносят весомый, иногда определяющий, вклад в экономику принимающих стран, но и способствуют развитию многообразных межгосударственных связей (причем не только в кооперативном направлении). В ряде государств министерства туризма приобретают значение, иногда сопоставимое с тем, которое имеют министерства иностранных дел.

Количество пользователей Интернета, насчитывавшее в 1998 г. 180 млн., а в 2007 - уже 1,3 млрд человек, достигает к 2010 г. 2 млрд. Предполагаемое число пользователей мобильными телефонами во всех странах достигало 5,28 млрд в конце 2010 г., по сравнению с 4,66 млрд в $2009 \Gamma^{2}$ Общемировой пассажиропоток международных авиарейсов, который в 1950 г. составлял 25 млн человек, а в 2007 г. уже 2,1 млрд человек, к 2014 г. достигнет, по прогнозам Международной ассоциации воздушного транспорта, 3,3 млрд чел. ${ }^{3}$

Общее число международных мигрантов в мире (включая легальных трудовых мигрантов и членов их семей), по оценкам Международной организации по миграции (МОМ), в 2010 г. превысило 215 млн человек ${ }^{4}$. По данным ФМС МВД России, в настоящее время в стране работает около 7 млн иностранцев: из них четыре миллиона трудятся на территории РФ на законных основаниях, но работают с нарушениями, остальные - находятся в стране нелегально ${ }^{5}$.

\footnotetext{
2 Число пользователей Интернетом достигло невероятной отметки // URL: http:/globalscience.ru/article/read/19096/

3 Мировой пассажиропоток к 2014 г. составит 3,3 млрд человек // URL: http://www.ato.ru/content/mirovoy-passazhiropotok-k-2014-godu-sostavit-33-mlrd-chelovek
}

4 Цит по: Алиев Магомед Далгатович. Россия в международных миграционных процессах: автореф. ... канд. экономических наук. СПб., 2011 // URL: http://worldec.ru/content/PhD/Aliev.pdf

5 ФМС: в РФ нелегально работают 3 млн трудовых мигрантов, остальные 4 млн «халтурят» с налогами // URL:
По оценкам центральных банков стран, в которых учитываются денежные средства, отправляемые работниками-мигрантами в страны происхождения, они составляют весьма значительные суммы. Так, например, в 2009 эти суммы достигали 42 млрд долл., отправленных из США, 16,2 млрд из Саудовской Аравии и более 6 млрд - из Швейцарии ${ }^{6}$. В целом же, согласно оценкам Всемирного банка, в 2012 г. страны, экспортирующие рабочую силу, получили от своих трудовых мигрантов более \$ 400 млрд, а через три года эта сумма может возрасти еще на треть 7 . Больше всех получают от своих эмигрантов Индия (\$70 млрд), Китай (\$66 млрд), Филиппины и Мексика (по \$24 млрд), Нигерия (\$21 млрд), Египет (\$18 млрд), Пакистан и Бангладеш (\$14 млрд), Вьетнам (\$9 млрд) и Ливия (\$7 млрд). Если сравнивать переводы с объемом ВВП, то в 2011 г. самую большую поддержку от своих эмигрантов получили Таджикистан (47\% ВВП), Либерия (31\%), Киргизия (29\%), Лесото (27\%), Молдавия (23\%), Непал (22\%), Самоа и Гаити (21\%), Ливия и Косово $(18 \%)^{8}$. В процентном отношении наибольшую сумму денежных средств отправляли для своей страны таджики - почти 50\% ВВП (\$3,8 миллиарда) ${ }^{9}$. Согласно специалистам из российского Института демографии, работающие в России трудовые мигранты только на Украину ежегодно переводят около 2 миллиардов евро ${ }^{10}$. Таким образом, доходы, которые мигранты пересылают своим семьям в страны происхождения, как и те, которые получают деятели искусства, профессионалы и научные работники, за свои выступления за рубежом, сопоставимы с доходами государств от крупных прямых международных инвестиций.

Наконец, в среде как политиков, так и исследователей существует практически полное единодушие относительно тех угроз глобальной безопасности и разрушительных для формирования более

http://www.newsru.com/russia/23nov2010/migranty.html. См. об этом также: Трудовая миграция // URL: http://www.staffexpert. ru/info/migrationrules/Trudovaya_migratsiya/

6 РФ в числе мировых лидеров и по числу трудовых мигрантов, и по объемам переводимых ими денег // Новые известия // URL: http://demoscope.ru/weekly/2010/0443/gazeta011.php. См. об этом также: Migration and Remittances // URL: www.worldbank.org/prospects/migrationandremittances

\footnotetext{
7 Квартиросдатчиков выведут на чистую воду // URL: http:// www.utro.ru/articles/2013/01/15/1094981.shtml

8 Всемирный банк: денежные переводы мигрантов растут без оглядки на кризис // Vedomosti.ru 22.11.2012 http://www. vedomosti.ru/finance/news/6366031/neissyakaemyj_istochnik

9 http://news.mail.ru/economics/11745698/

10 http://rss.novostimira.com/n_3821503.html
} 


\section{Международные отношения International Relations}

справедливого и стабильного мирового порядка вызовов, которые представляют собой действия нелегитимных НГА. Происходит расползание мафиозных структур по всему миру. Транснациональный терроризм создает свои гнезда не только в слаборазвитых странах с нестабильными политическими режимами и вербует адептов не только среди наиболее обездоленных слоев населения. Его сети проникают и в самые экономически и политически благополучные, «состоявшиеся» государства, где он находит сторонников как в среде иммигрантов, так и в числе вполне обеспеченных и «успешных» коренных граждан. Наркотрафик представляет реальную угрозу экономической, социальной и даже политической безопасности как для отдельных стран, так и для мирового развития в целом.

Таким образом, массовое вторжение негосударственных акторов в мировую политику представляет собой бесспорно важный феномен, трансформирующий ее как в количественном, так и в качественном отношении. Не случайно уже с конца прошлого века вопрос об отношениях между НГА и государствами стал предметом обширной исследовательской литературы и породил оживленную теоретическую дискуссию, значение которой выходит за сугубо академические рамки. Резюмируя ход этой дискуссии и ее современное состояние, можно выделить три точки зрения.

Первая из них трактует отношения государственных и негосударственных международных акторов с либерально-революционаристских позиций. В данном случае вопрос о влиянии НГА акцентируется в трех аспектах. Во-первых, это утверждения о вытеснении государств на второстепенные роли в мировой политике, об их ослаблении, упадке и даже отмирании под натиском транснациональных акторов ${ }^{11}$. Во-вторых, это тезис о моральном превосходстве «альтруистичских» НПО над государствами-эгоистами ${ }^{12}$. В-третьих, это положение о «реванше гражданского общества» над государством и о формировании «глобального гражданского общества» ${ }^{13}$.

\footnotetext{
11 См., напр.: Strobe Talbott, «Globalization and Diplomacy: A Practitioner's Perspective», Foreign Policy, hiver 1997.

12 Bertrand Badie. De la souveraineité à la capacité de l'État // Marie-Claude Smouts (dir.): Les Nouvelles Relations internationales. Pratiques et théories. Paris: Presses de Sciences Po, 1998, pp. 46 et 50.

13 См., напр.: Florini Ann M. The Third Force. The Rise of International Society. - Wachington^ ${ }^{\wedge}$ Carnegy Endowment for Internationa Peace. 2000; Schechter Michael G. The Revival of Civil Sosiety: Global and Comparative Perspectives. New York: St. Martin's Press. 1995.
}

Сторонники другой, консервативно-реалистской позиции, склонны указывать на структурообразующую роль государств как элементов международной системы. Государства, с этой точки зрения, представляют собой гораздо более устойчивые политические единицы, чем любой из транснациональных акторов. Важность негосударственных субъектов и очевидность масштабов транснациональной деятельности, как настаивал К. Уолц, сами по себе не подтверждают вывод об устарелости государственно-ориентированных концепций международной политики ${ }^{14}$.

Большинство же исследователей, аналитиков и экспертов не отрицают растущего влияния НГА на международные отношения и мирополитические процессы. В то же время они отмечают, что хотя соотношение сил между государствами и НГА, конечно, изменилось, данный факт не приводит к перевороту в мировой политике.

Настаивая на такой позиции, многие известные международники призывают преодолеть затянувшуюся стадию романтизации легитимных НГА, критикуя противопоставление «двух миров» мира НПО, как альтруистов, обладателей «морального лица», выразителей прогрессивного общественного мнения и солидарности формирующегося глобального гражданского общества, миру государств, как холодных монстров, концентрирующихся на собственных сугубо эгоистических интересах, априорно виновных во всех бедствиях и судорожно цепляющихся за остатки своего неминуемо уходящего в прошлое суверенитета. Подобные взгляды, с их точки зрения, не имеют под собой серьезной основы и оторваны от действительности ${ }^{15}$.

Во-первых, они носят ангажированный и идеологический характер. Трактуя государство как абсолютное зло, упадок которого является необходимым и желательным, они представляют собой не столько научные подходы, сколько верования, назначения которых в том, чтобы убедить себя и других в пришествие более демократического мира, управляемого более гуманными способами.

\footnotetext{
14 Kenneth Waltz. Theory of International Politics. McGrawHill. 1979, p. 95.

15 См., напр.: William Wallace, Daphne Josseline. Non-State Actor in World Politics. Basingstoke, Palgrave, 2002, p. 36-37; M.-C. Smouts, D. Battistella, P. Vennesson. Dictionnaire des relations internationales. Approches. Concepts. Doctrines. Paris, Dalloz, 2003, p. 379; Samy Cohen. La Résistance des États. La démocratie face aux défis de la mondialisation. Éd. du Seuil, 2003 , p.53-54; Гай Питерс. Глобализация, управление и его институты. // Отечественные записки № 2 (16) 2004 // url: http://www.strana-oz.ru/?numid $=17 \&$ article $=808$
} 


\section{Актуальный вопрос /}

Live issue

Во-вторых, они переоценивают как ослабление государства, так и влияние НГА, сваливая в одну кучу возникновение «новых угроз» (таких, как транснациональный терроризм, наркотрафик, распространение ОМУ и т.п), с одной стороны, и рост влияния таких НГА как бизнес-структуры, НПО, иммигранты - с другой. Однако влияние этих феноменов на государство глубоко различно. Не все из них ведут к снижению его возможностей. Если организованная преступность действительно становится угрозой для государства, то этого нельзя сказать об НПО, многие из которых сотрудничают с ним и даже выполняют от его имени ряд задач, например, в оказании гуманитарной помощи, ликвидации последствий природных катастроф и т.п. Реальное взаимодействие государств и легитимных НГА опровергает идею об имманентном антагонизме между статоцентричным и мультицентичным мирами.

В-третьих, легитимные НГА - не монолит, так же, как и мир государственных акторов. Разные типы легитимных негосударственных игроков имеют разные отношения с государствами, преследуя разные цели и оказывая на них разное влияние. Транснациональные бизнес-структуры в большинстве своем имеют более прочные связи с государствами происхождения, чем это принято иногда считать. Многие из НГА неспособны существовать без поддержки со стороны государств или МПО. Между неправительственными организациями и правительствами нередко наблюдается больше солидарности, чем между самими НПО, конкурирующими друг с другом за внимание общественности и за финансовую поддержку.

Как подчеркивает С.Коэн, идея о том, что все НПО являются альтруистическими и хотят служить благу человечества в противовес государствам, имеющим только эгоистические интересы, вытекает из широко распространенного клише. Мир НПО многообразен. Среди них есть респектабельные организации с репутацией независимости и эффективности в той помощи, которую они оказывают угнетаемому или обездоленному населению, отстаивают права человека или всеобщие интересы защиты окружающей среды. И есть НПО, созданные правительствами для защиты своих интересов GONGO (Governmental Oriented Non Governmental Organizations). Между этими двумя крайностями существует множество самых разных НПО, более или менее серьезных, более или менее независимых, более или менее некоммерческих ${ }^{16}$.

16 Samy Cohen. La Résistance des États. La démocratie face aux défis de la mondialisationé Éd. du Seuil, 2003, p. 18-57.
B-четвертых, подлинная природа НГА не всегда является прозрачной. Некоторые из НПО представляют собой эманацию государства, замаскированного в частные ассоциации. В таких случаях грят о «квазиHПO» (QUANGO). В конечном итоге НПО несут ответственность только перед своими спонсорами, что приводит их к нескончаемым поискам фондов, медийной поддержки, новых сторонников... и своих врагов, ибо "каждая НПО ревниво относится к своей автономии, воспринимая ее как условие своей выживаемости" ${ }^{\prime 17}$.

Наконец, в-пятых, НПО - это западный дискурс. Он представляет собой только часть существующих мировых культур, хотя претендует на всеобщность ${ }^{18}$. Однако в последние десятилетия глобальная политика находится в процессе серьезной мутации, сутью которой является утрата Западом монополии на управление миром и становление полицентричного мирового порядка ${ }^{19}$. Переходный этап в мировом развитии сопровождается нарастанием межгосударственных противоречий и кризисов, формированием новых центров силы, обострением конкурентной борьбы в сферах экономики, политики, социальных отношений. В такой обстановке государства стремятся использовать все возможности для укрепления своих позиций, в том числе путем привлечения на свою сторону легитимных (а в отдельных случаях и нелегитимных) НГА, а также использования их потенциала для ослабления позиций конкурентов. Как подчеркивает Гай Питерс: «Если только у государства появляется возможность прибегнуть к помощи и авторитету частных организаций, оно обязательно попытается ими воспользоваться, но при этом будет на самом деле стараться упрочить свое собственное влияние и авторитет» ${ }^{20}$.

Вторжение негосударственных акторов в мировую политику - бесспорный, общепризнанный факт, принимаемый сегодня в расчет всеми государствами при формировании ими своей международной политики и оказывающий влияние на глобальную повестку дня. В основе данного феномена лежат такие взаимосвязанные причины, как

\footnotetext{
17 M.-C. Smouts, D. Battistella, P. Vennesson. Dictionnaire des relations internationales. Approches. Concepts. Doctrines. - Paris, Dalloz, 2003, p.379.

18 См. об этом: Jean-François Guilhaudis. Relations internationales contemporaines. Paris: Ed. du Juris-Classeur, 2002; Samy Cohen. La Résistance des États. Op. cit; M.-C. Smouts, D. Battistella, P. Vennesson. Dictionnaire des relations internationales. Op. cit.

19 См. об этом: Закария Ф. Постамериканский мир. М.: Издво «Европа». 2009.

20 Гай Питерс. Цит. соч.
} 


\section{Международные отношения International Relations}

небывалые достижения научно-технологического прогресса в области электроники, средств связи, транспорта, массовых коммуникаций; транснационализация производства, товаров, услуг и идей; глобализация экономики, формирование мирового рынка и либерализация торговли; интенсификация всех видов международных обменов. Вместе с тем, истоки массовизации и политической активности НГА связаны с интересами наиболее развитых государств, последовательно упраздняющих препятствия для международных обменов, контроль за движением капиталов и финансовыми рынками и информационными потоками.

НГА не представляют собой однородного ансамбля, однонаправлено воздействующего на мировую политику. Напротив, по своему составу это достаточно сложный конгломерат самых разнородных элементов. Их поведение далеко не всегда отличается ясностью. Широкая палитра интересов, стремлений, целей и ценностей, разрозненность мотиваций действий, о которой иногда можно только догадываться, делают трудно предсказуемыми их реакции на те или иные события.

Дискуссионным остается даже сам термин, призванный объединять их в единое целое. Еще в большей мере это касается типологии НГА. Вместе с тем, в большинстве случаев существует согласие относительно таких типов НГА как нелегитимные и легитимные. К первым относят насильственных акторов (VNSA), международные ОПГ (в том числе в сети Интернет), террористические сети. Ко вторым МНПО, бизнес-структуры, глобальные частные СМИ и Интернет-сообщество.

Главный недостаток дискуссии о взаимовлиянии и взаимодействии государственных и негосударственных участников международных отношений и мировой политики состоит в том, что она нередко сводится к манихейскому спору по принципу: «или - или». Между тем, подобный под- ход затемняет реально существующие императивы, приобретающие фундаментальный характер для современной мировой политики. Во-первых, это императив организации политического сотрудничества в борьбе против таких связанных с нелегитимными НГА угроз международной безопасности, как транснациональный терроризм и международная организованная преступность. Во-вторых, это потребность соединения поддержки инициатив и активности легитимных НГА с укреплением международной стабильности. Оба императива требуют согласования, а не противопоставления национальных и групповых интересов и ценностей ведущих государств. Между тем, ценность международной стабильности сегодня все чаще подвергается сомнению в пользу ценности демократических перемен и безусловной поддержки действий легитимных (или выдаваемых за таковых) НГА, которые однозначно трактуются как выразители прогрессивных демократических тенденций. Однако дилемма “демократические преобразования или стабильность” носит ложный характер. В контексте рассматриваемой проблематики - в том числе в ее внутригосударственном измерении - она исходит из плоской интерпретации как мотивов поведения и однородности состава НГА, так и содержания международной стабильности. Последняя подается как застой, отсутствие перемен, подавление демократических тенденций, что не соответствует действительности, ибо на самом деле мир нуждается в динамической стабильности, которая предполагает развитие как неизбежность перемен. "Стабильность характеризует способность системы обеспечивать назревшие, необходимые для ее самосохранения перемены"21. При этом речь идет о сохранении мирополитической системы как таковой, а не о «замораживании» того или иного ее состояния или той или иной конфигурации.

\section{Источники:}

1. Абашидзе А.Х., Урсин Д.А. Неправительственные организации: международно-правовые аспекты. - М., 2002.

2. Гай Питерс. Глобализация, управление и его институты // Отечественные записки № 2 (16) 2004 // URL: http://www.strana-oz.ru/?numid=17\&article $=808$

3. Демоскоп Weekly. № 513-514, 4-17 июня 2012.

4. Зонова Т.В. Дипломатия: Модели, формы, методы: учебник для вузов. - М.: Аспект Пресс. 2013. Гл. 4.

5. Кузнецова Е.В. Международные неправительственные организации. URL: www.fir.bsu.by/chairs/il/.../ kuznetsova_INGO_uchebnoe_posobie.pdf

21 См. об этом: Богатуров А.Д., Косолапов Н.А., Хрусталев М.А. Очерки теории и политического анализа международных отношений. М.: МОНФ, 2002. 
6. Лариса Пермякова. Мэры городов-мегаполисов - новые «старые» участники дипломатических отношений // URL: http://russiancouncil.ru/blogs/diplomacy/?id_4=113

7. Наумов А.О. Международные неправительственные организации в современной мирополитической системе. - М.: КРАССАНД. 2009.

8. Негосударственные участники мировой политики / под ред. М.М. Лебедевой и М.В. Харкевича. - М.: Изд-во МГИМО, 2013.

9. Закария Ф. Постамериканский мир. - М.: Изд-во “Европа”. 2009.

10. Analyzing Non-State Actors in World Politics, by Gustaaf Geeraerts // URL: http://poli.vub.ac.be/publi/polepapers/pole0104.htm

11. Samy Cohen. La Résistance des États. La démocratie face aux défis de la mondialisationé Éd. du Seuil, 2003.

\section{References (transliteration):}

1. Abashidze A.H., Ursin D.A. Nepravitel'stvennye organizacii: mezhdunarodno-pravovye aspekty. - M., 2002.

2. Gai Piters. Globalizaciya, upravlenie i ego instituty // Otechestvennye zapiski. № 2 (16) 2004 // URL:http:// www.strana-oz.ru/?numid=17\&article=808

3. Demoskop Weekly. № 513-514, 4-17 iyunya 2012.

4. Zonova T.V. Diplomatiya: Modeli, formy, metody: uchebnik dlya vuzov. - M.: Aspekt Press. 2013. Gl. 4.

5. Kuznecova E.V. Mezhdunarodnye nepravitel'stvennye organizacii // URL: www.fir.bsu.by/chairs/il/.../kuznetsova_INGO_uchebnoe_posobie.pdf

6. Larisa Permyakova. Mery gorodov-megapolisov - novye «starye» uchastniki diplomaticheskih otnoshenii // URL: http://russiancouncil.ru/blogs/diplomacy/?id_4=113

7. Naumov A.O. Mezhdunarodnye nepravitel'stvennye organizacii v sovremennoi miropoliticheskoi sisteme. - M.: KRASSAND. 2009.

8. Negosudarstvennye uchastniki mirovoi politiki / pod red. M.M. Lebedevoi i M.V. Harkevicha. — M.: Izd-vo MGIMO, 2013.

9. Zakariya F. Postamerikanskii mir. - M.: Izd-vo «Evropa». 2009. 